\title{
Effect of Printing Parameters on the Thermal and Mechanical Properties of 3D-Printed PLA and PETG, Using Fused Deposition Modeling
}

\author{
Ming-Hsien Hsueh ${ }^{1, *} \mathbb{0}$, Chao-Jung Lai ${ }^{2, *}$, Shi-Hao Wang ${ }^{1}$, Yu-Shan Zeng ${ }^{1}$, Chia-Hsin Hsieh ${ }^{1}$, Chieh-Yu Pan ${ }^{3, *}$ \\ and Wen-Chen Huang $4, *$ \\ 1 Department of Industrial Engineering and Management, National Kaohsiung University of Science \\ and Technology, Kaohsiung 807618, Taiwan; shwang@nkust.edu.tw (S.-H.W.); tzen010@gmail.com (Y.-S.Z.); \\ charlie820906@gmail.com (C.-H.H.) \\ 2 Department of Fashion Design and Management, Tainan University of Technology, Tainan 71002, Taiwan \\ 3 Department and Graduate Institute of Aquaculture, National Kaohsiung University of Science \\ and Technology, Kaohsiung 811213, Taiwan \\ 4 Department of Information Management, National Kaohsiung University of Science and Technology, \\ Kaohsiung 824005, Taiwan \\ * Correspondence: mhhsueh@nkust.edu.tw (M.-H.H.); t30129@mail.tut.edu.tw (C.-J.L.); \\ panjade@nkust.edu.tw (C.-Y.P.); wenh@nkust.edu.tw (W.-C.H.)
}

check for

updates

Citation: Hsueh, M.-H.; Lai, C.-J.; Wang, S.-H.; Zeng, Y.-S.; Hsieh, C.-H.; Pan, C.-Y.; Huang, W.-C. Effect of Printing Parameters on the Thermal and Mechanical Properties of 3D-Printed PLA and PETG, Using Fused Deposition Modeling. Polymers 2021, 13, 1758. https://doi.org/ $10.3390 /$ polym 13111758

Academic Editor: Fouad Erchiqui

Received: 7 May 2021

Accepted: 24 May 2021

Published: 27 May 2021

Publisher's Note: MDPI stays neutral with regard to jurisdictional claims in published maps and institutional affiliations.

Copyright: (c) 2021 by the authors. Licensee MDPI, Basel, Switzerland. This article is an open access article distributed under the terms and conditions of the Creative Commons Attribution (CC BY) license (https:/ / creativecommons.org/licenses/by/ $4.0 /)$.

\begin{abstract}
Fused Deposition Modeling (FDM) can be used to manufacture any complex geometry and internal structures, and it has been widely applied in many industries, such as the biomedical, manufacturing, aerospace, automobile, industrial, and building industries. The purpose of this research is to characterize the polylactic acid (PLA) and polyethylene terephthalate glycol (PETG) materials of FDM under four loading conditions (tension, compression, bending, and thermal deformation), in order to obtain data regarding different printing temperatures and speeds. The results indicated that PLA and PETG materials exhibit an obvious tensile and compression asymmetry. It was observed that the mechanical properties (tension, compression, and bending) of PLA and PETG are increased at higher printing temperatures, and that the effect of speed on PLA and PETG shows different results. In addition, the mechanical properties of PLA are greater than those of PETG, but the thermal deformation is the opposite. The above results will be a great help for researchers who are working with polymers and FDM technology to achieve sustainability.
\end{abstract}

Keywords: 3D printing; FDM; PLA; PETG; mechanical properties; thermal deformation; sustainability

\section{Introduction}

Due to global competition, the mass customization of products, and the long molding cycle of traditional manufacturing methods, the manufacturing industry is under more pressure to seek the advantages of new processes that can cope with small batches and rapid manufacturing. In recent years, 3D printing technology in the medical, manufacturing, and engineering fields has developed rapidly [1,2]. This technology is also known as Additive Manufacturing (AM) technology, which is based on incremental layer-by-layer manufacturing [3]. It is not only directly fabricated from 3D digital models but it also does not require any fixtures or specific tools. It can manufacture complex structures and print multi-materials quickly, compared to any other method. AM technology can be divided into three basic groups, namely those that are solid-based, powder-based, and liquid-based. The three most commonly used techniques are Fused Deposition Modeling (FDM) [4,5], Selective Laser Sintering (SLS) [6,7], and stereolithography (SLA) [8,9], where FDM is solid-based, SLS is powder-based, and SLA is liquid-based.

FDM is the first choice of AM technology for polymer and composite materials, due to its flexibility, higher printing speed, low cost, high strength and toughness, non- 
toxicity, and the diversity of materials, in comparison with other AM technologies. A spool of thermoplastic material, in the form of filaments, is most commonly used in FDM technology to produce the 3D parts. Firstly, the thermoplastic materials (e.g., ABS, PLA, PC, PS, Nylon, and PET) are melted by a heated liquefier to extrude the filaments through a nozzle. The thermoplastic filaments are in a semi-solid state during the extrusion. After this, the nozzle can move in an $\mathrm{X}-\mathrm{Y}$ direction to deposit semi-solid filaments onto the plane, and then it cools, solidifies, and integrates with the surrounding filaments. After a layer is deposited, the build platform is moved downward in a Z-direction, and another layer is deposited onto the previous layer. Therefore, FDM can manufacture any complex geometrical and internal structures and has become one of the most popular AM technologies. Nowadays, the technology of FDM is widely applied in many industries, such as the biomedical, manufacturing, aerospace, automobile, industrial, and building industries [10-13]. However, FDM is deposited layer by layer, so the adhesion between the layers is weak, and its mechanical properties are poor, in comparison to injection molding. In addition, it is a complex process and many process parameters need to be adjusted, which will influence the quality and properties of the parts. Therefore, the quality and properties of the parts can be improved by setting a reasonable range of process parameters.

In order to avoid the loss of printing materials and time, as noted by other researchers, this study discusses the effect of printing parameters on the thermal and mechanical behavior of PLA and PETG, and printing parameters include the temperature and the speed of printing. The recommended printing temperature for PLA ranges from $180^{\circ} \mathrm{C}$ to $210^{\circ} \mathrm{C}$, while the recommended printing temperature for PETG ranges from $215^{\circ} \mathrm{C}$ to $235^{\circ} \mathrm{C}$.

\section{Literature Review}

Over the past several years, researchers have explored the influence of the process parameters of printing on the key metrics of FDM technology to improve the quality and the properties of the parts, in order to guarantee a reliable structural performance and to decrease the building cycle.

Jiang et al. [14] explored the tensile strength and the fiber distribution of PLA, ABS, PETG, and Amphora by adding corban fiber, with the raster angle of the printing being $0^{\circ}, 45^{\circ}, \pm 45^{\circ}$, and $90^{\circ}$, respectively. The results showed that PETG had the highest tensile strength after adding corban fiber. In particular, when the raster angle was set at $0^{\circ}$, the tensile strength and the Young's modulus increased to $48.2 \%$ and $313.2 \%$, respectively. Mansour et al. [15] explored the compressive strength, nano-indentation, and modal parameters of PETG by adding a 20\% mixture of carbon fiber, and the results showed that the specimen's compressive strain decreased by $66 \%$ after adding a mixture of carbon fiber, while the modal and hardness increased to $30 \%$ and $27 \%$, respectively, and the damping and loss factors also decreased from $17.3 \%$ and $15.3 \%$ to $13.8 \%$ and $12.39 \%$, respectively. Santana et al. [16] explored the differences among the mechanical properties of PLA and PETG, based on FDM and injection molding technology, and the results showed that PLA has higher stiffness and tension than PETG; however, PETG has better thermal degradation resistance and thermal stability than PLA, and, after the FDM process, the tensile strength of PLA and PETG increases by $24 \%$ and $18 \%$, respectively. Because the homoscedasticity of PETG is lower than that of PLA, PETG should have better printing stability. Rajpurohit et al. [17] explored the effect of the angle and width of the grid and layer height on PLA, and the results showed that, when the angle of the grid is $0^{\circ}$, it has the highest tensile strength, and that the tensile strength can be improved by enhancing the width of the grid and reducing the layer height. Valerga et al. [18] analyzed the effects of the printing temperature, humidity, and the color of the wire on the mechanical properties, based on PLA, and the results showed that a higher printing temperature will enhance the deviation of the product size and reduce the tensile strength, while the deviation will increase substantially when the printing temperature is over $200{ }^{\circ} \mathrm{C}$. As far as the mechanical properties are concerned, the printing temperature should be set at 
$220^{\circ} \mathrm{C}$. Vinyas et al. [19] studied composites of PLA, such as PLA $+30 \%$ nylon glass fibers, PLA $+10 \%$ carbon fibers, and a PLA + PET-G polymer blend, after analyzing the tensile strength and heat-resistance, and the results showed that PLA $+10 \%$ carbon fibers had the highest tensile strength. Meanwhile, PLA $+30 \%$ glass fibers could provide excellent thermal stability and can be used where primary importance is given to thermal stability over the mechanical strength. Singh et al. [20] divided ABS, PLA, and High-Impact Polystyrene (HIPS) into three slices and changed the order of printing to produce test specimens. They analyzed the tensile strength by arranging the different materials, and the results showed that the tensile strength of the specimens increased to $10.78 \mathrm{Mpa}$ by printing in three layers, with the first layer in ABS, the second layer in PLA, and the last layer in HIPS. Yao [21] explored the effects of different layer thicknesses on the UTS of PLA, including 0.1, 0.2, and $0.3 \mathrm{~mm}$, with a raster angle of $0^{\circ}, 15^{\circ}, 30^{\circ}, 45^{\circ}, 60^{\circ}, 75^{\circ}$, and $90^{\circ}$, respectively. The results showed that the raster angle affected the UTS significantly, and the discrepancy between the specimens of $0.1 \mathrm{~mm}-0^{\circ}$ and $0.1 \mathrm{~mm}-90^{\circ}$ reached $52.29 \%$. The present paper shows the effect of printing parameters on the mechanical properties of the materials. The researchers used different methods, including adjusting the parameters, adding other fibers, changing the process, and so on, to improve the efficiency, productivity, and mechanical characteristics of the printing objects. Barrios et al. [22] explored the parameters needed to ensure that a PETG wire had the best Ca value, based on FDM, including the layer height, nozzle temperature, process speed, the acceleration of the process speed, and the flow of material. After analyzing them using the Taguchi method and Analysis of Variance (ANOVA) methods, the results showed that the acceleration of the process speed and the flow of the material had the strongest influence on the quality parameters of PETG. Guessasma et al. [23] explored the effect on the tensile strength of PETG by setting the nozzle temperature at $210^{\circ} \mathrm{C} 250^{\circ} \mathrm{C}$, and the results showed that the PETG wire must be printed at a temperature of over $230^{\circ} \mathrm{C}$; otherwise, the material cannot be pasted onto the platform. When the nozzle temperature is set at $250{ }^{\circ} \mathrm{C}$, the porosity has a maximum value of $2 \%$ and the average roughness is approximately $100 \mu \mathrm{m}$. In addition, the FDM process will reduce the tensile strength and stiffness of PETG by over $40 \%$, and the elongation will also decrease drastically. The present paper on PETG shows that it has better heat resistance than PLA, and, therefore, many producers are expected to use PETG in the future, in order to compensate for the disadvantages of PLA. Many researchers have explored a large amount of data on PLA, based on FDM, and if the parameters of PLA and PETG could be cross-referenced, the printing parameters of PETG could be evaluated by the data history of PLA in the future. Bakradze et al. [24] present a heuristic procedure for determining the key processing parameters (PPs) of PA and ABS; the results showed that it is possible to reduce the optimization time down to several hours, as well as to reduce the amount of consumed feedstock material. Tensile tests revealed a strong effect of the amorphous and semi-crystalline nature of the polymer on the results of optimization.

\section{Materials and Methods}

\subsection{D Printing Machine and Printing Materials}

The 3D printer used in this study is the X1E produced by INFINITY 3DP Co., Ltd. (Kaohsiung, Taiwan). It uses a 1/32 micro-stepping motor, so that the slide rail is more stable when moving. This study mainly compared the material properties of PLA and PETG. Therefore, the size of the selected nozzle was $0.4 \mathrm{~mm}$ to reduce the complexity of the study, and the main structure and the support structure were printed by the same nozzle. The printing temperature of the nozzle can reach up to $300{ }^{\circ} \mathrm{C}$. The temperature of the platform can reach up to $110^{\circ} \mathrm{C}$. The specifications of the 3D printer are shown in Table 1 . The materials that were tested were polylactic acid (PLA) and polyethylene terephthalate glycol (PETG) from the Min-Yau Information Co., Ltd. (New Taipei, Taiwan), which are both strongly thermoplastic. Before printing, the PLA and PETG materials were placed in a humidity control box to keep them dry. The specifications of the printing materials are shown in Table 2. 
Table 1. The specifications of the 3D printer.

\begin{tabular}{cc}
\hline Model & X1E \\
\hline Physical dimensions & $($ w $) 40 \mathrm{~cm} \times(\mathrm{d}) 22 \mathrm{~cm} \times(\mathrm{h}) 46 \mathrm{~cm}$ \\
\hline Maximum printing area & $(\mathrm{w}) 21 \mathrm{~cm} \times(\mathrm{d}) 21 \mathrm{~cm} \times(\mathrm{h}) 24 \mathrm{~cm}$ \\
\hline Print layer height & $0.04 \sim 0.32 \mathrm{~mm}$ \\
\hline Wire diameter & $\Phi 1.75 \mathrm{~mm}$ \\
\hline Nozzle diameter & $0.2,0.4,0.6 \mathrm{~mm}$ \\
\hline Platform temperature & $\sim 110^{\circ} \mathrm{C}$ \\
\hline Nozzle printing temperature & $\sim 300{ }^{\circ} \mathrm{C}$ \\
\hline Cooling method & $4.5 \mathrm{~cm}$ turbo fan \\
\hline Motor drive & $1 / 32$ micro-stepping motor (8825 driver chip) \\
\hline
\end{tabular}

Table 2. The specifications of the printing materials.

\begin{tabular}{ccc}
\hline Name & \multicolumn{2}{c}{ Specification } \\
\hline Material & PLA & PETG \\
\hline Color & Snow white & Matt black \\
\hline Wire diameter & $1.75 \pm 0.05 \mathrm{~mm}$ & $1.75 \pm 0.05 \mathrm{~mm}$ \\
\hline Weight & $800 \mathrm{~g}$ & $800 \mathrm{~g}$ \\
\hline Recommended printing temp & $180 \sim 210{ }^{\circ} \mathrm{C}$ & $215 \sim 235{ }^{\circ} \mathrm{C}$ \\
\hline Recommended printing speed & $30 \sim 50 \mathrm{~mm} / \mathrm{s}$ & $30 \sim 50 \mathrm{~mm} / \mathrm{s}$ \\
\hline
\end{tabular}

\subsection{Printing Procedure and Parameters}

Firstly, SolidWorks software was used to create a 3D virtual geometry of the test specimens. Since most slicing software accepts image files in .obj and .stl format, the SolidWorks file was converted to .stl format and was exported into the slicing software after creating the virtual test specimens. The slicing software uses KISSlicer software because the system of this software has more parameters that can be adjusted, in order to print more detailed test specimens. Since the melting and freezing points of the two printing materials in this experiment were different, if PETG was printed at the same printing speed and temperature as PLA, it would increase the probability of the object warping and threads pulling or peeling off the printing platform. Therefore, the selected printing speed and temperature range were different, as shown in Table 3. The fixed parameter conditions included an infill density of $20 \%$, a raster angle of $45^{\circ}$, a layer thickness of $0.2 \mathrm{~mm}$, and a platform temperature of $25^{\circ} \mathrm{C}$. The $\mathrm{X}, \mathrm{Y}, \mathrm{Z}$ labels used for the specimen orientation are shown in Figure 1. The quality of a 3D-printed object depends on the quality of the initial 3D model of the object; therefore, the image acquisition step is essential to the quality of the 3D-printed object [24-26]. The three different requirements of printing quality are: (i) low surface roughness, (ii) good mechanical properties, and (iii) short printing time. This study discusses the mechanical properties of printing quality. 
Table 3. Process parameter conditions of the printing material.

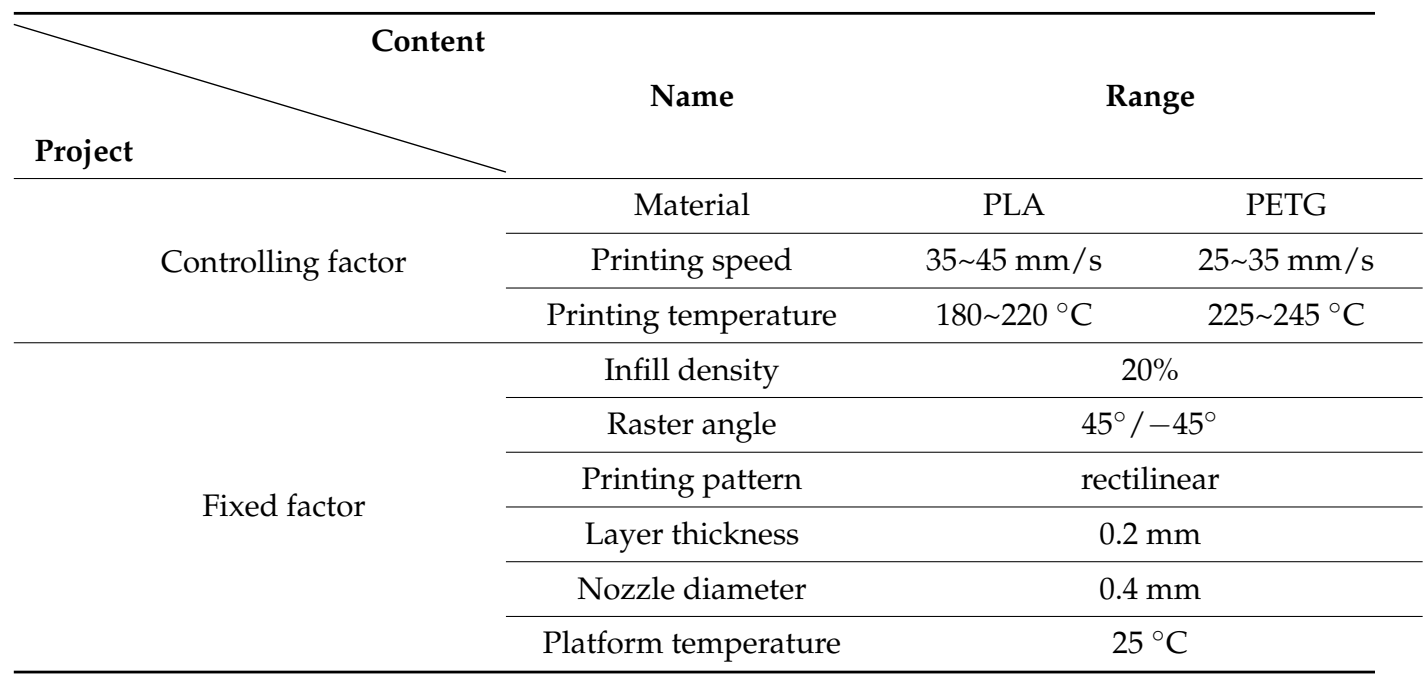

(a)

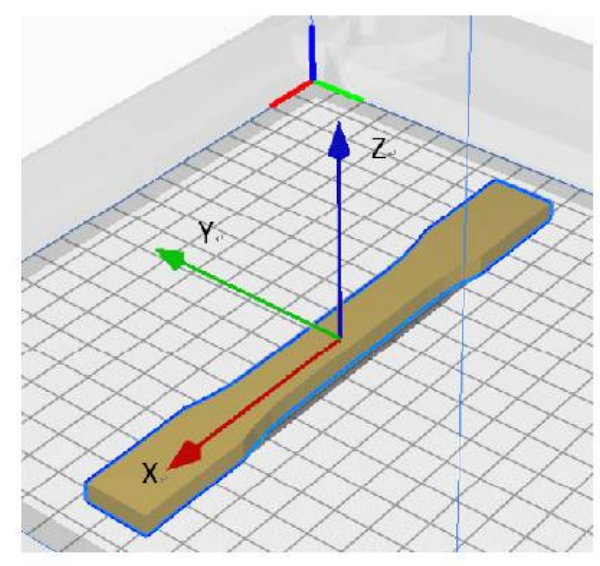

(b)

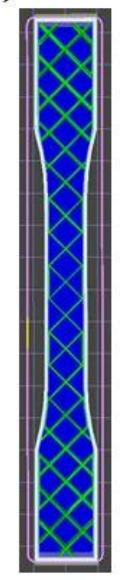

Figure 1. (a) Definition of the specimen orientations; (b) dimensions and trajectories used for monolayer samples.

\subsection{The Tensile, Compression, and Bending Test}

To evaluate the tensile, compression, and bending properties of the specimens, the test was performed using the QC-H51A2 universal testing machine, the specifications of which are shown in Table 4 . The specimens were tested at a rate of $5 \mathrm{~mm} / \mathrm{min}$ and at room temperature, kept at $23^{\circ} \mathrm{C}$. The stress and strain data of the test, with a force of $100 \mathrm{kN}$, were recorded by the built-in program. The data obtained from the tests were analyzed by using Excel software to determine the values of Young's modulus and the ultimate strength of the specimens. The tensile specimens were prepared according to ASTM D638 standard testing, the compression specimens were prepared according to ASTM D3410 standard testing, and the bending specimens were prepared according to ASTM D790 standard testing. 
Table 4. The specifications of the QC-H51A2 universal testing machine.

\begin{tabular}{cc}
\hline Model & H51A2 \\
\hline Capacity & $100 \mathrm{kN}$ \\
\hline Stroke & $1100 \mathrm{~mm}$ (without fixture) \\
\hline Space & $\varnothing 550 \mathrm{~mm}$ \\
\hline Load resolution & $1 / 10,000($ maximize $1 / 200,000)$ \\
\hline Displacement resolution & $0.001 \mathrm{~mm}$ \\
\hline Motor & Servo motor \\
\hline Speed & $0.003 \sim 375 \mathrm{~mm} / \mathrm{min}$ \\
\hline Height & $2200 \mathrm{~mm}$ \\
\hline Weight & $800 \mathrm{kgf}$ \\
\hline Sampling rate & $500 \mathrm{~Hz}(\mathrm{Max})$. \\
\hline Current & $15 \mathrm{~A}$ \\
\hline
\end{tabular}

\subsection{The Thermal Deformation Test}

The thermal deformation test was performed to evaluate the thermal deformation properties of the specimens, using the QC-654 heat deflection tester. The specimen was placed on the Charpy of the structure, and the main function was a test of the center position of $0.445 \mathrm{MPa}$ or a bending stress of $1.82 \mathrm{MPa}$. The test environment temperature was increased by $2{ }^{\circ} \mathrm{C} / \mathrm{min}$, in order to measure the specimen's center of deformation, with a $0.25 \mathrm{~mm}$ temperature value as the deformation temperature. This test is suitable for material at $27^{\circ} \mathrm{C}$, which is still a hard material. The thermal deformation specimens were prepared according to ASTM D648 standard testing, while the specifications of the QC-654 heat deflection tester are shown in Table 5.

Table 5. The specifications of the QC-654 heat deflection tester.

\begin{tabular}{cc}
\hline Model & QC-654 \\
\hline Temperature & Room temperature $\sim 300{ }^{\circ} \mathrm{C}$ \\
\hline Temperature control & Temperature rise speed $2{ }^{\circ} \mathrm{C} / \mathrm{min}$ \\
\hline Weight sets & Basic weight support load is $3 \mathrm{~N}$. Each test fixture will enclose the below quantities: \\
& $0.1 \mathrm{~N} \times 1,0.2 \mathrm{~N} \times 2,0.5 \mathrm{~N} \times 1,1 \mathrm{~N} \times 1,2 \mathrm{~N} \times 2,5 \mathrm{~N} \times 1,10 \mathrm{~N} \times 1$ \\
\hline Deformation & $0.01 \sim 10 \mathrm{~mm}$ \\
\hline Span & $100 \mathrm{~mm}$ (max.) adjustable $50 \mathrm{~mm}$ \\
\hline Radius of support & Camber $\mathrm{R}$ angle $3.0 \mathrm{~mm}$ \\
\hline Test quantity & Mechanical gauge $0.01 \sim 10 \mathrm{~mm}$ \\
& Electronic gauge $0.001 \sim 10 \mathrm{~mm}$ \\
& PLC control $0.001 \sim 10 \mathrm{~mm}$ \\
& Set: $1,2,3,6$ set \\
\hline
\end{tabular}

\section{Results and Discussion}

Each graph of mechanical and thermal properties was obtained by the average value of four replicates over five experiments. Figure 2 presents the stress-strain curves of the tensile tests. It can be seen that the material properties of PLA are similar to an elastic-plastic response, the material properties of PETG are similar to a brittle response, and the break strain increases with the decreasing printing speed [27]. The stress-strain curves of PLA are similar for printing temperatures up to a strain value of around 0.01 , except for a printing temperature of $180{ }^{\circ} \mathrm{C}$ (Figure $2 \mathrm{a}-\mathrm{c}$ ), at which the PLA material has not completely reached melting point. The stress-strain curves of PETG are similar for all printing temperatures 
(Figure $2 \mathrm{~d}-\mathrm{f}$ ), because PETG melts completely at a printing temperature of over $225^{\circ} \mathrm{C}$. It can be seen that the tensile strength is equal to the break stress and seems to be independent of the printing temperature.
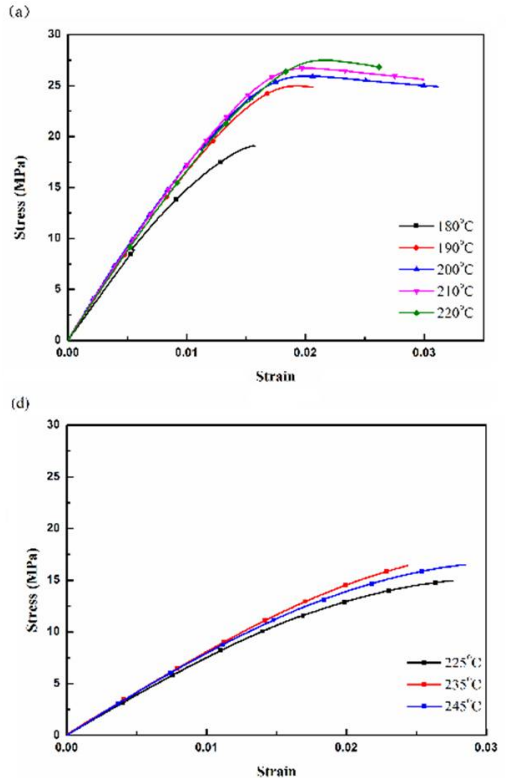
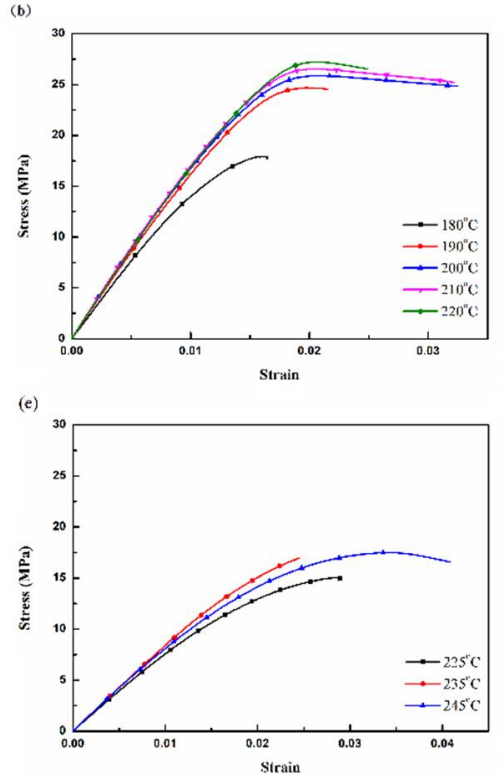
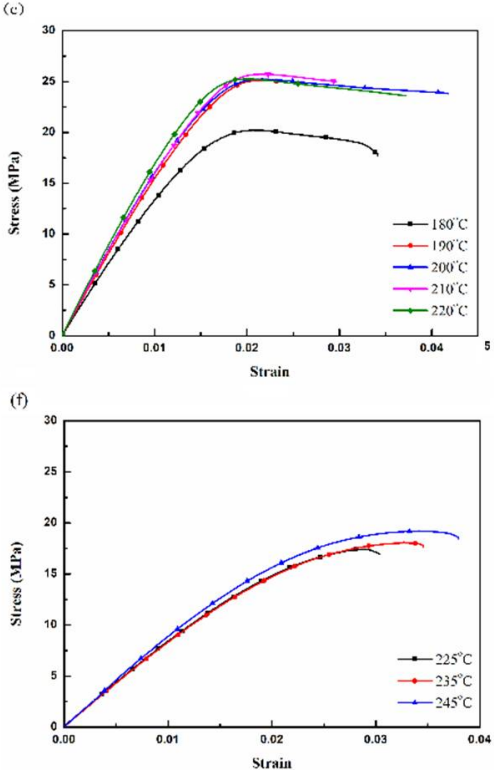

Figure 2. Stress-strain curves of tensile tests $(\mathbf{a}-\mathbf{c}) 45$ to $35 \mathrm{~mm} / \mathrm{s}$ of printing speeds for PLA specimens, and (d-f) 35 to 25 $\mathrm{mm} / \mathrm{s}$ of printing speeds for PETG specimens.

Figure 3 shows the tensile properties (Young's modulus and strength) of PLA and PETG specimens at different printing temperatures and speeds. It can be seen that the low fluidity and high viscosity of the polymer melt at a low temperature can result in poor bonding and high porosity between the lines and layers of the molten polymer [18,28]. Therefore, the tensile properties are poor at low printing temperatures. As the printing temperature increases, the viscosity of the PLA and PETG melts decreases, which results in increased fusion between the polymer fuse and the layers, and the porosity decreases. Therefore, the tensile properties are increased accordingly and those for PLA are higher than those for PETG. The scanning electron microscope (SEM) micrographs of the references [29] taken from fracture planes support the above reasoning. The tensile properties of PLA increase when the printing speed increases, because the heat dissipates rapidly and it has a low filling rate, as the fusion between the layers improves. The tensile properties of PETG increase when the printing speed decreases, and because its heat dissipation is slow, it has low porosity.

(a)

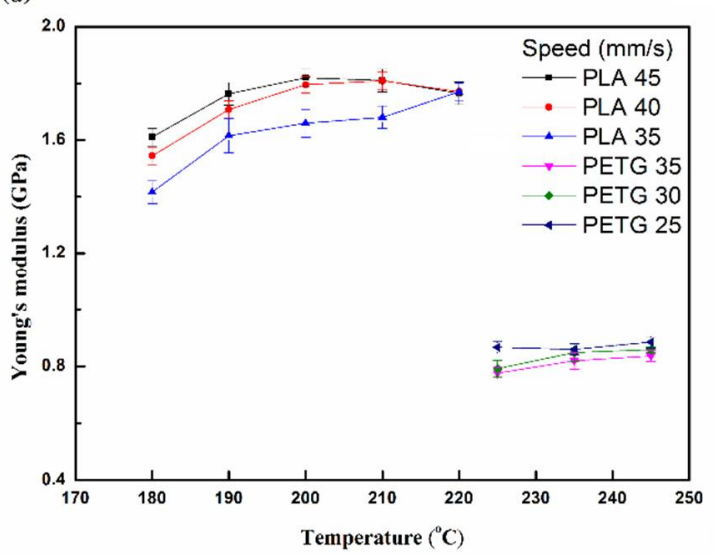

(b)

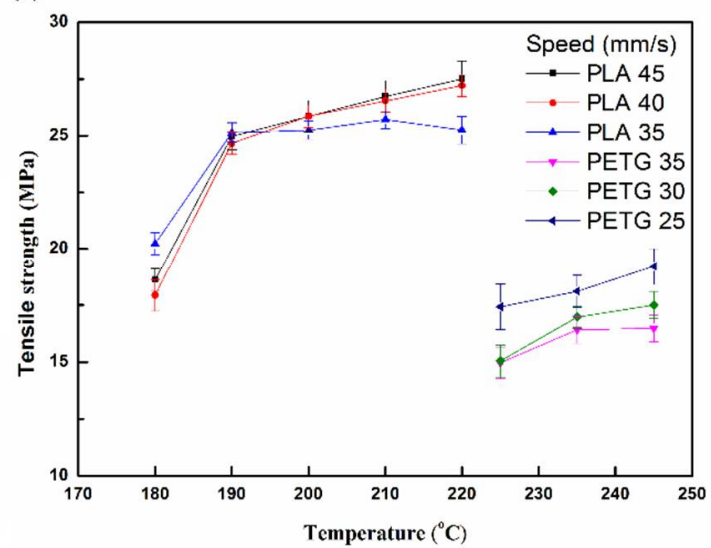

Figure 3. (a) Young's modulus and (b) tensile strength of PLA and PETG specimens after tensile tests at different printing temperatures and printing speeds. 
Figure 4 shows images of the PLA and PETG specimens at different printing temperatures after the tensile tests. The printing temperatures increase from left to right. Two failure modes are defined, namely an interlayer failure mode and an in-layer failure mode $[30,31]$. It can be observed that there are different stress distributions at each printing temperature and that the failures follow the weaker areas of the pattern. The layer bonds increase with the increasing printing temperature. An interlayer failure mode occurred when the layer bonds of the specimens were insufficient, and it failed along the 45 line of the upper layer. In addition, most of the failure planes of the in-layer failure mode were approximately perpendicular to the material layer. These results agree with those obtained in previous studies.

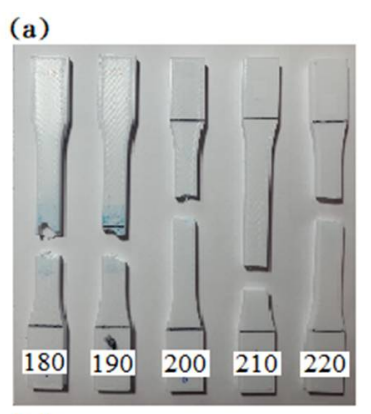

(d)

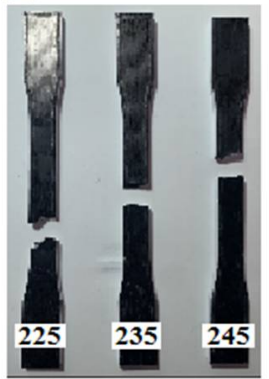

(e) (b)
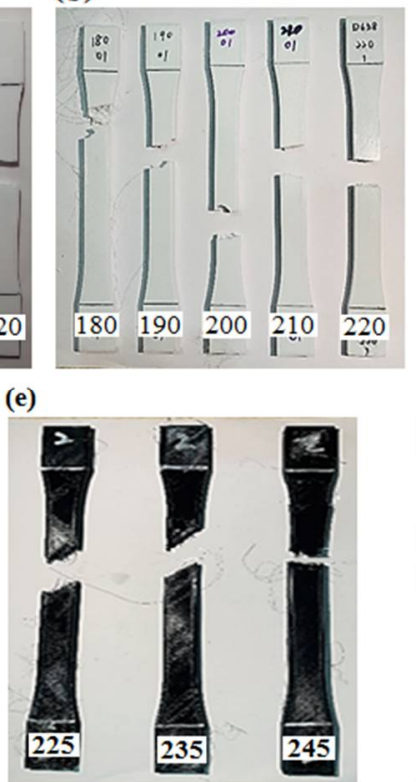

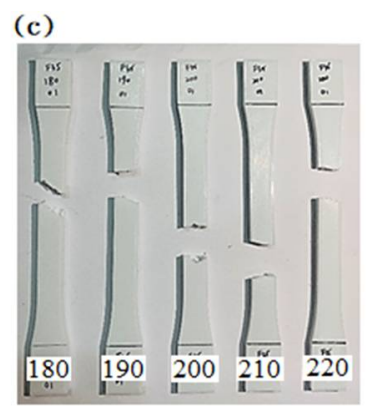

(f)

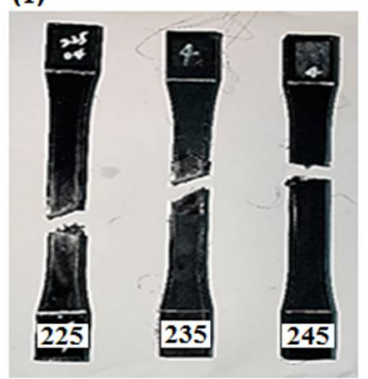

Figure 4. Images of $(\mathbf{a}-\mathbf{c})$ PLA specimens and (d-f) PETG specimens after tensile tests. The printing speed decreases from (a) to (f): 45, 40, 35, 35, 30, and $25 \mathrm{~mm} / \mathrm{s}$.

Figure 5 shows the compression properties (Young's modulus and strength) of the PLA and PETG specimens at different printing temperatures and speeds. From all the results, it was found that the values of the compression properties increase with the increasing printing temperature. This is due to the decrease in the contact stress at the line and line contacts. It was observed that there was a minimal effect on the compression properties of PETG with respect to the printing speed. The stress in compression largely exceeded that measured in the tension, for any given strain. A strong tension and compression asymmetry was observed [32,33]. This was caused by the residual stress, which was due to the cooling down of the specimen to room temperature. In addition, the compression properties of PLA were greater than those of PETG, similar to their tensile properties.

Figure 6 shows the bending properties (Young's modulus and strength) of PLA and PETG specimens at different printing temperatures. The most remarkable finding regarding the graphics related to the strength is that the bending value is considerably higher than in the compressive and tensile strengths because of the residual stress [34]. The graphics show that the compressive Young's modulus is higher than that of the bending Young's modulus and the tensile Young's modulus. The tensile properties are the lowest, regardless of Young's modulus and strength. In addition, the bending properties of PLA are greater than those of PETG, similar to their tensile properties and compression properties [35].

Figure 7 presents the thermal deformation of the PLA and PETG specimens at different printing temperatures. It can be seen that the PLA specimens $(45 \mathrm{~mm} / \mathrm{s})$ have a higher thermal deformation temperature than the PETG specimens $(40$ and $35 \mathrm{~mm} / \mathrm{s}$ ). The PETG specimens $(25 \mathrm{~mm} / \mathrm{s})$ have a higher thermal deformation temperature than the PLA 
specimens ( 30 and $35 \mathrm{~mm} / \mathrm{s}$ ). The result shows that PETG performs better than PLA in terms of heat resistance, which may be because the glass transition temperature of PETG is higher than that of PLA [16].

(a)

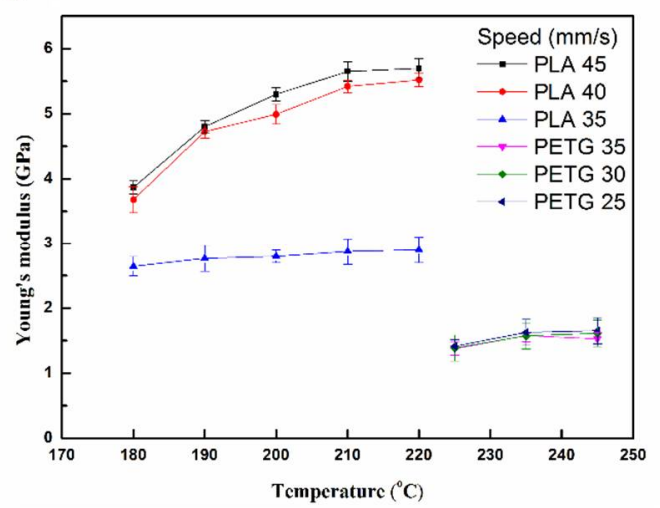

(b)

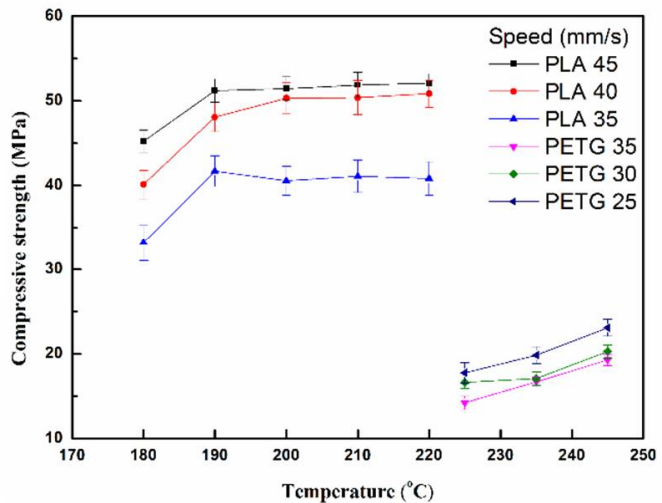

Figure 5. (a) Young's modulus and (b) compressive strength of PLA and PETG specimens after compression tests at different temperatures and printing speeds.
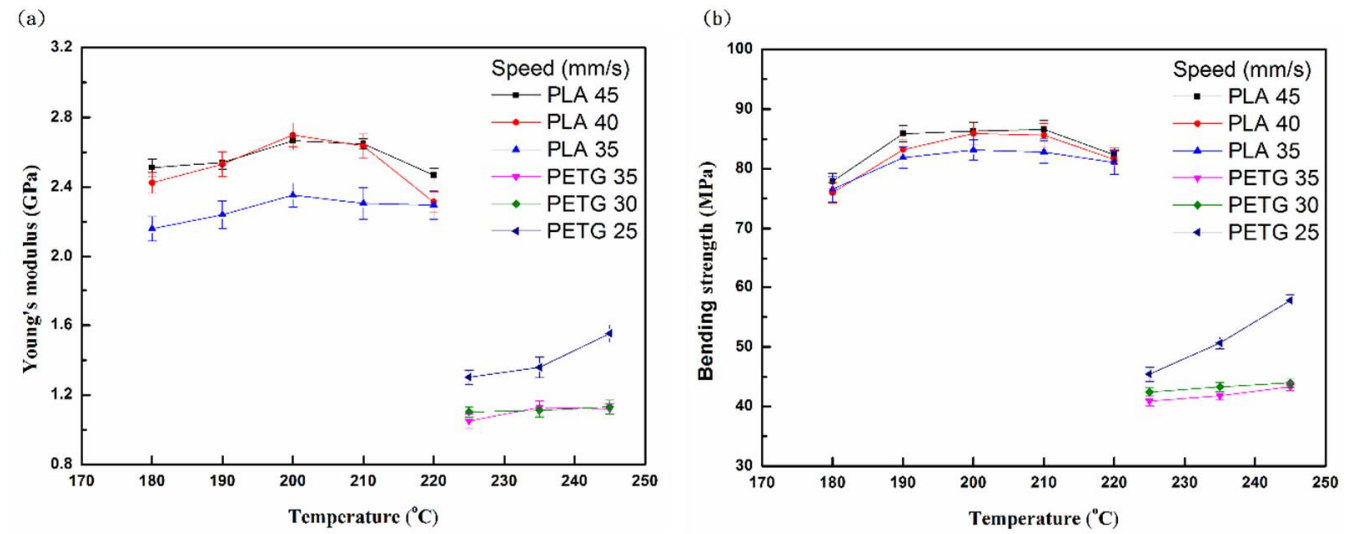

Figure 6. (a) Young's modulus and (b) bending strength of PLA and PETG specimens after bending tests at different temperatures and printing speeds.

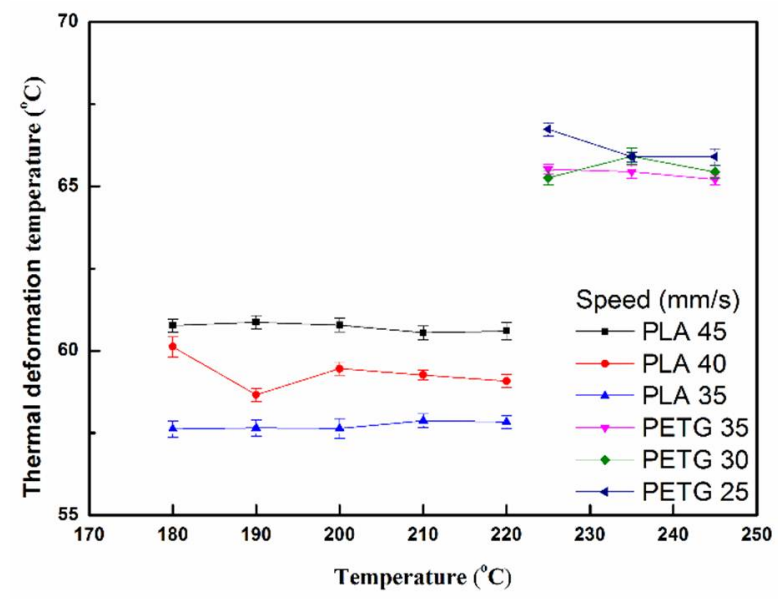

Figure 7. Thermal deformation temperature of PLA and PETG specimens at different printing temperatures and printing speeds. 


\section{Conclusions}

The effect of the printing temperature and printing speed on the PLA and PETG constructed by FDM was investigated. The mechanical properties (tensile, compression, and bending) and thermal properties of the specimens were tested. The main conclusions are as follows:

1. PLA and PETG materials exhibit obvious tensile and compression asymmetry, and the compressive stress exceeds the tensile stress.

2. As the printing temperature increases, the mechanical properties of the PLA and PETG materials increase.

3. As the printing speed increases, the mechanical properties of the PLA material increase, but the mechanical properties of the PETG material decrease.

4. The mechanical properties of PLA are greater than those of PETG, regardless of the Young's modulus and strength, but the opposite is the case for the thermal deformation.

5. In this article, despite the PLA and PETG being below the $20 \%$ infill density conditions, the compressive strength is higher than the tensile strength, but lower than the bending strength, with a bending Young's modulus that is higher than the tensile Young's modulus but lower than the compressive Young's modulus.

Author Contributions: M.-H.H. guided the research direction, found the solutions and designed the approach to set up the testing facility, designed and executed mechanical tests; C.-J.L. wrote the initial draft of the paper; S.-H.W., Y.-S.Z., C.-H.H. conducted the experiments and collected the results. C.-Y.P., W.-C.H. analyzed experimental results in this study. All authors have read and agreed to the published version of the manuscript.

Funding: This paper is supported by the Ministry of Science and Technology (MOST) and the National Kaohsiung University of Science and Technology under MOST-109-2622-E-992-015-CC3.

Acknowledgments: The author would like his thank to the Ministry of Science and Technology (MOST) and the National Kaohsiung University of Science and Technology for their financial support during this study.

Conflicts of Interest: The authors declare no conflict of interest.

\section{References}

1. Luis, E.; Pan, H.M.; Bastola, A.K.; Bajpai, R.; Sing, S.L.; Song, J.; Yeong, W.Y. 3D printed silicone meniscus implants: Influence of the 3D printing process on properties of silicone implants. Polymers 2020, 12, 2136. [CrossRef]

2. Luis, E.; Pan, H.M.; Sing, S.L.; Bajpai, R.; Song, J.; Yeong, W.Y. 3D direct printing of silicone meniscus implant using a novel heat-cured extrusion-based printer. Polymers 2020, 12, 1031. [CrossRef]

3. Alaimo, G.; Marconi, S.; Costato, L.; Auricchio, F. Influence of meso-structure and chemical composition on FDM 3D-printed parts. Compos. Part B Eng. 2017, 113, 371-380. [CrossRef]

4. Masood, S.H. Intelligent rapid prototyping with fused deposition modelling. Rapid Prototyp. J. 1996, 2, 24-33. [CrossRef]

5. Wang, S.; Ma, Y.; Deng, Z.; Zhang, S.; Cai, J. Effects of fused deposition modeling process parameters on tensile, dynamic mechanical properties of 3D printed polylactic acid materials. Polym. Test. 2020, 86, 106483. [CrossRef]

6. Kumar, S. Selective laser sintering: A qualitative and objective approach. JOM 2003, 55, 43-47. [CrossRef]

7. Bai, J.; Yuan, S.; Chow, W.; Chua, C.K.; Zhou, K.; Wei, J. Effect of surface orientation on the tribological properties of laser sintered polyamide 12. Polym. Test. 2015, 48, 111-114. [CrossRef]

8. Mansour, S.; Gilbert, M.; Hague, R. A study of the impact of short-term ageing on the mechanical properties of a stereolithography resin. Mater. Sci. Eng. A 2007, 447, 277-284. [CrossRef]

9. Ni, R.; Qian, B.; Liu, C.; Liu, X.; Qiu, J. A cross-linking strategy with moderated pre-polymerization of resin for stereolithography. RSC Adv. 2018, 8, 29583-29588. [CrossRef]

10. Kumar, L.J.; Krishnadas Nair, C.G. Current trends of additive manufacturing in the aerospace industry. In Advances in $3 D$ PrintingEAdditive Manufacturing Technologies; Springer: Singapore, 2017; pp. 39-54. [CrossRef]

11. Zadpoor, A.A.; Malda, J. Additive manufacturing of biomaterials, tissues, and organs. Ann. Biomed. Eng. 2017, 45, 1-11. [CrossRef]

12. Wolfs, R.J.M.; Bos, F.P.; Salet, T.A.M. Early age mechanical behaviour of 3D printed concrete: Numerical modelling and experimental testing. Cem. Concr. Res. 2018, 106, 103-116. [CrossRef] 
13. Panda, B.; Lim, J.H.; Tan, M.J. Mechanical properties and deformation behaviour of early age concrete in the context of digital construction. Compos. Part B Eng. 2019, 165, 563-571. [CrossRef]

14. Jiang, D.; Smith, D. Anisotropic mechanical properties of oriented carbon fiber filled polymer composites produced with fused filament fabrication. Addit. Manuf. 2017, 18, 84-94. [CrossRef]

15. Mansour, M.; Tsongas, K.; Tzetzis, D.; Antoniadis, A. Mechanical and Dynamic Behavior of Fused Filament Fabrication 3D Printed Polyethylene Terephthalate Glycol Reinforced with Carbon Fibers. Polym. Plast. Technol. Eng. 2018, 57, 1715-1725. [CrossRef]

16. Santana, L.; Alves, J.; Sabino Netto, A.; Merlini, C. Estudo comparativo entre PETG e PLA para Impressão 3D através de caracterização térmica, química e mecânica. Matéria (Rio de Janeiro) 2018, 23. [CrossRef]

17. Rajpurohit, S.; Dave, H. Effect of process parameters on tensile strength of FDM printed PLA part. Rapid Prototyp. J. 2018, 24, 1317-1324. [CrossRef]

18. Valerga, A.; Batista, M.; Salguero, J.; Girot, F. Influence of PLA Filament Conditions on Characteristics of FDM Parts. Materials 2018, 11, 1322. [CrossRef]

19. Vinyas, M.; Athul, S.J.; Harursampath, D.; Nguyen Thoi, T. Experimental evaluation of the mechanical and thermal properties of 3D printed PLA and its composites. Mater. Res. Express 2019, 6, 115301. [CrossRef]

20. Singh, R.; Kumar, R.; Farina, I.; Colangelo, F.; Feo, L.; Fraternali, F. Multi-material additive manufacturing of sustainable innovative materials and structures. Polymers 2019, 11, 62. [CrossRef] [PubMed]

21. Yao, T.; Deng, Z.; Zhang, K.; Li, S. A method to predict the ultimate tensile strength of 3D printing polylactic acid (PLA) materials with different printing orientations. Compos. Part B Eng. 2019, 163, 393-402. [CrossRef]

22. Barrios, J.; Romero, P. Improvement of surface roughness and hydrophobicity in PETG parts manufactured via fused deposition modeling (FDM): An application in 3D printed self-cleaning parts. Materials 2019, 12, 2499. [CrossRef]

23. Guessasma, S.; Belhabib, S.; Nouri, H. Printability and tensile performance of 3D printed polyethylene terephthalate glycol using fused deposition modelling. Polymers 2019, 11, 1220. [CrossRef] [PubMed]

24. Bakradze, G.; Arājs, E.; Gaidukovs, S.; Thakur, V.K. On the heuristic procedure to determine processing parameters in additive manufacturing based on materials extrusion. Polymers 2020, 12, 3009. [CrossRef]

25. Rengier, F.; Mehndiratta, A.; von Tengg-Kobligk, H.; Zechmann, C.M.; Unterhinninghofen, R.; Kauczor, H.U.; Giesel, F.L. 3D printing based on imaging data: Review of medical applications. Int. J. Comput. Assist. Radiol. Surg. 2010, 5, 335-341. [CrossRef] [PubMed]

26. Wu, H.C.; Chen, T.C.T. Quality control issues in 3D-printing manufacturing: A review. Rapid Prototyp. J. 2018, $24,607-614$. [CrossRef]

27. Petersmann, S.; Spoerk, M.; Steene, W.V.D.; Üçal, M.; Wiener, J.; Pinter, G.; Arbeiter, F. Mechanical properties of polymeric implant materials produced by extrusion-based additive manufacturing. J. Mech. Behav. Biomed. Mater. 2020, 104, 103611. [CrossRef] [PubMed]

28. Ding, Q.; Li, X.; Zhang, D.; Zhao, G.; Sun, Z. Anisotropy of poly(lactic acid)/carbon fiber composites prepared by fused deposition modeling. J. Appl. Polym. Sci. 2020, 137, 48786. [CrossRef]

29. Behzadnasab, M.; Yousefi, A.A.; Ebrahimibagha, D.; Nasiri, F. Effects of processing conditions on mechanical properties of PLA printed parts. Rapid Prototyp. J. 2020, 26, 381-389. [CrossRef]

30. Fernandez-Vicente, M.; Calle, W.; Ferrandiz, S.; Conejero, A. Effect of infill parameters on tensile mechanical behavior in desktop 3D printing. 3D Print. Addit. Manuf. 2016, 3, 183-192. [CrossRef]

31. Yao, T.; Ye, J.; Deng, Z.; Zhang, K.; Ma, Y.; Ouyang, H. Tensile failure strength and separation angle of FDM 3D printing PLA material: Experimental and theoretical analyses. Compos. Part B 2020, 188, 107894. [CrossRef]

32. Song, Y.; Li, Y.; Song, W.; Yee, K.; Lee, K.Y.; Tagarielli, V.L. Measurements of the mechanical response of unidirectional 3D-printed PLA. Mater. Des. 2017, 123, 154-164. [CrossRef]

33. Patibandla, S.; Mian, A. Layer-to-layer physical characteristics and compression behavior of 3D printed polymer metastructures fabricated using different process parameters. J. Elastomers Plast. 2020, 009524432093999. [CrossRef]

34. Pastor-Artigues, M.M.; Roure-Fernández, F.; Ayneto-Gubert, X.; Bonada-Bo, J.; Pérez-Guindal, E.; Buj-Corral, I. Elastic asymmetry of PLA material in FDM-printed parts: Considerations concerning experimental characterisation for use in numerical simulations. Materials 2019, 13, 15. [CrossRef] [PubMed]

35. Santana, L.; Alves, J.L.; Sabino-Netto, A.C.; Merlini, C. A comparative study between PETG and PLA for 3D Printing through thermal, chemical and mechanical characterization. Matéria (Rio J.) 2018, 23. [CrossRef] 